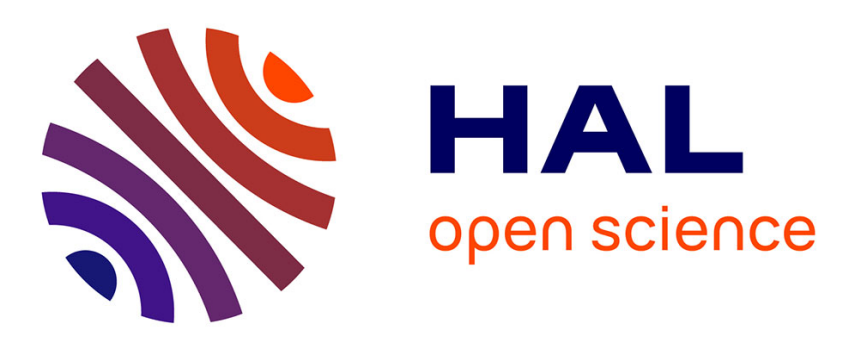

\title{
The evaluation of ischaemia-modified albumin as a marker of myocardial ischaemia in end stage renal disease
}

Rajan Sharma, David C Gaze, Paul O Collinson, Denis Pellerin, Helen Gregson, Christopher P Streather, Stephen J Brecker

\section{To cite this version:}

Rajan Sharma, David C Gaze, Paul O Collinson, Denis Pellerin, Helen Gregson, et al.. The evaluation of ischaemia-modified albumin as a marker of myocardial ischaemia in end stage renal disease. Clinical Science, 2007, 113 (1), pp.25-32. 10.1042/CS20070015 . hal-00479362

\section{HAL Id: hal-00479362 https://hal.science/hal-00479362}

Submitted on 30 Apr 2010

HAL is a multi-disciplinary open access archive for the deposit and dissemination of scientific research documents, whether they are published or not. The documents may come from teaching and research institutions in France or abroad, or from public or private research centers.
L'archive ouverte pluridisciplinaire HAL, est destinée au dépôt et à la diffusion de documents scientifiques de niveau recherche, publiés ou non, émanant des établissements d'enseignement et de recherche français ou étrangers, des laboratoires publics ou privés. 
THE EVALUATION OF ISCHEMIA MODIFIED ALBUMIN AS A MARKER OF MYOCARDIAL ISCHAEMIA IN END STAGE RENAL DISEASE

Dr Rajan Sharma ${ }^{1}$ MD, Dr David Gaze ${ }^{2}$ PHD, Dr Denis Pellerin ${ }^{4}$ PHD, Mr Rajnikant L Mehta ${ }^{5}$ MSC, Ms Helen Gregson ${ }^{3}$ BSC, Dr Christopher P Streather FRCP, Dr Paul O Collinson ${ }^{2}$ FRCPath, Dr Stephen J D Brecker ${ }^{1}$ MD FRCP.

Departments of ${ }^{1}$ Cardiology, ${ }^{2}$ Chemical Pathology and ${ }^{3}$ Renal Medicine, St

George's Hospital, London

${ }^{4}$ The Heart Hospital, London

${ }^{5}$ Department of Medical Statistics, Southampton University Hospital

Addressee for correspondence:

Dr Rajan Sharma

Ealing Hospital NHS Trust

Uxbridge Road,

Southall, Middlesex UB1 3HW

E-Mail Address: rajdoc.Sharma@tiscali.co.uk

Telephone Number: 02089673181

Fax Number: 02089675260

Conflict of interest: none.

Total Word Count: 4715. 


\begin{abstract}
Background. The early diagnosis of myocardial ischaemia is problematic in patients with end stage renal disease (ESRD). The study aim was to determine whether Ischemia Modified Albumin (IMA) rises during dobutamine stress and detects myocardial ischaemia in patients with ESRD.
\end{abstract}

Methods. 114 renal transplant candidates were prospectively studied. All received dobutamine stress echocardiography (DSE). IMA levels were taken at baseline and 1 hour after cessation of DSE. Results: 35 patients (31\%) had a positive DSE result. Baseline IMA levels were not significantly different in the DSE positive and negative groups. The rise in IMA was significantly higher in the DSE positive group compared to those with no ischaemic response $(26.5 \pm 19.1 \mathrm{KU} / \mathrm{L}$ vs $8.2 \pm 9.6 \mathrm{KU} / \mathrm{L}, \mathrm{p} 0.007)$. From ROC analysis, the optimal IMA rise to predict an ischaemic response was 20 KU/L, with sensitivity $81 \%$ and specificity $72 \%(\mathrm{AUC}=0.80,95 \%$; CI $0.44,0.94 ; \mathrm{p}$ $=0.03)$. There were 18 deaths, 10 cardiac over a follow up period of $2.25 \pm 0.71$ years. An IMA rise $\geq 20 \mathrm{KU} / \mathrm{L}$ was associated with significantly worse survival ( $\mathrm{p}=$ 0.02). Conclusions: IMA is a moderately accurate marker of myocardial ischaemia in ESRD. Patients with an IMA rise $\geq 20 \mathrm{KU} / \mathrm{L}$ during DSE had significantly worse survival. 


\section{KEYWORDS}

Ischaemia Modified Albumin

End Stage Renal Disease

Myocardial Ischaemia

Dobutamine Stress Echocardiography

Renal transplantation

Acute Coronary Syndrome 


\section{INTRODUCTION}

Patients with end stage renal disease (ESRD) have significantly higher mortality after acute myocardial infarction (MI) than non uraemic patients.[1, 2] A meta analysis of ST segment elevation acute MI trials showed an inverse correlation between 30 day mortality and renal function.[3] Patients with renal failure and non ST segment elevation acute coronary syndrome (ACS) have higher 30 day and 180 day mortality than non uraemic patients. $[4,5]$ The need to promptly diagnose, risk stratify and treat patients with suspected ACS is therefore essential. However, the diagnosis in ESRD is often problematic. Silent ischaemia is common[6] and a large proportion have abnormal baseline ECG's[7] and elevated baseline cardiac troponin levels.[8, 9]

Ischemia modified albumin (IMA) is a novel biomarker of acute myocardial ischaemia with high sensitivity but moderate specificity.[10, 11] The accuracy of IMA for ischaemia diagnosis in ESRD has not been previously reported. We have previously reported that baseline IMA levels do predict mortality in patients with ESRD.[12] Using the same patient population, the aim of this exploratory study was to determine whether an IMA rise during dobutamine stress echocardiography (DSE) detects myocardial ischaemia in patients with ESRD. DSE was chosen to provoke an ischaemic response because we have recently shown this technique has high sensitivity and specificity for coronary artery disease diagnosis in renal transplant candidates.[13] 


\section{METHODS}

This study was performed in accordance with the declaration of Helsinki. Informed consent was obtained from all patients.

\section{Population}

Between January 2003 and December 2004, 114 consecutive patients referred for renal transplantation evaluation at St George's Hospital, London were prospectively studied. Exclusion criteria were: age less than 18 years, severe aortic stenosis, unstable angina and inability to consent. Clinicians reporting echocardiography and coronary angiography data were blinded to the biochemical data. The echocardiography and coronary angiography results were used to determine suitability for renal transplantation and whether revascularisation was required.

\section{Dobutamine Stress Echocardiography}

The General Electric Vingmed System 7 was used. For those on dialysis, the studies were performed $16-24$ hours post dialysis, when patients were most likely to be closest to their euvolaemic state.[14] Two- dimensional measurements were performed at baseline as recommended by the American Society of Echocardiography.[15] Left atrial diameter was determined from parasternal M mode recordings, with the cursor placed at the tips of the aortic valve leaflets and left atrium. Measurements were averaged over three cardiac cycles. Transmitral inflow was recorded by placing the pulsed wave Doppler sample volume at the mitral valve leaflet tips in the apical 4-chamber view. Peak velocity of early filling (E) was recorded from the Doppler trace. From pulsed wave real time tissue Doppler images obtained in the apical 4 - chamber view, early diastolic (Ea) mitral annular velocities 
were measured. The sample volume was placed at the lateral mitral annulus. LV filling pressure was estimated from the mitral E/Ea ratio.[16]

Beta blockers were discontinued 72 hours prior to DSE but all other anti-hypertensive and anti - ischaemic medication taken up to the day of the examination. Images were acquired in standard parasternal long- and short-axis and apical 2-, 3-, 4-chamber views at baseline and during stepwise infusion of dobutamine infusion, given according to a protocol based on 3 minute stages of $5,10,20,30,40 \mu \mathrm{g} / \mathrm{kg} / \mathrm{min}$. Atropine was administered up to a total of $1.0 \mathrm{mg}$ intravenously if the target heart rate was not achieved with dobutamine alone. Blood pressure and 12-lead ECG were recorded at each infusion stage. Baseline, low-dose (heart $10-15$ beats above baseline), peak and recovery (10 minutes after drug infusion terminated) stage images were stored and analysed in digital quad screen format. The test was stopped if: (a) the target heart rate was achieved ([220 - age] x 0.85), (b) ST depression $>2 \mathrm{~mm}$ occurred, (c) significant tachyarrhythmia (sustained supraventricular tachycardia or a $>3$ beat run of ventricular tachycardia) occurred, (d) symptomatic severe hypotension (systolic blood pressure $<80 \mathrm{~mm} \mathrm{Hg}$ ) occurred, (e) blood pressure exceeded $240 \mathrm{mmHg}$ systolic or $140 \mathrm{mmHg}$ diastolic.

All images were reported off-line by 2 experienced observers blinded to the rest of the study. Qualitative analysis was performed with the left ventricle divided into a 17 segment model. Regional wall motion was described as hyperkinetic, normal, hypokinetic, akinetic and dyskinetic. Results were classified as a normal response with an overall increase in wall motion or abnormal response. An abnormal response was described by the occurrence under stress of hypokinesia, akinesia, or dyskinesia in 1 or more resting normal segments and/or worsening of wall motion in 1 or more 
resting hypokinetic segments.[17] The resting and peak wall motion index (WMSI) score was calculated. The level of agreement, kappa $(\kappa$,$) between the 2$ sonographers was $\kappa=0.82$. Consensus was obtained in discordant cases.

\section{Coronary Angiography}

Coronary angiograms were interpreted blindly by 2 experienced observers and consensus obtained for disagreement. The level of agreement was $\kappa=0.85$. Stenosis severity of each epicardial artery was assessed visually and graded as follows: normal, mild ( $<50 \%$ luminal narrowing), moderate (50 to $70 \%$ luminal narrowing), significant ( $>70 \%$ luminal narrowing). Severe CAD was defined as luminal stenosis $>$ $70 \%$ in 1 or more epicardial artery.

\section{Sample Acquisition}

Whole blood venous samples were collected at baseline and 60 minutes after peak dobutamine stress. Samples were allowed to clot and were centrifuged at $3000 \mathrm{rpm}$ for 10 minutes. Serum was decanted and frozen until analysis.

\section{Cardiac Troponin T (cTnT) Assay}

cTnT was measured using the third generation TROP T STAT assay on an Elecsys 2010 immunoassay system (Roche Diagnostics, Lewes).[18] The assay detection limit was $<0.01 \mu \mathrm{g} / \mathrm{L}$. The total assay coefficient of variation $(\mathrm{CV})$ was $5.5 \%$ at $0.32 \mu \mathrm{g} / \mathrm{L}$ and $5.4 \%$ at $6.0 \mu \mathrm{g} / \mathrm{L}$. The corresponding concentration with a $10 \% \mathrm{CV}$ was 0.03 $\mu \mathrm{g} / \mathrm{L}$. The $99^{\text {th }}$ percentile of 350 healthy subjects was found to be $0.01 \mu \mathrm{g} / \mathrm{L}$. For this study, a cTnT level $\geq 0.05 \mu \mathrm{g} / \mathrm{L}$ was taken as positive. This is the value suggested for acute MI diagnosis.[19] 


\section{Ischaemia modified albumin (IMA)}

Serum IMA was measured by the albumin cobalt binding (ACB) test (Ischemia Technologies Inc, Denver, Colorado, USA) on a Cobas MIRA PLUS instrument (ABX diagnostics, London, UK). The first generation ACB test has been validated and described previously.[20, 21] We used a second generation ACB test and in our laboratory the assay coefficient of variation was $5.09 \%$ in the range of 56.67 to 66.57 $\mathrm{KU} / \mathrm{L}$ and $3.05 \%$ in the range 147.17 to $158.03 \mathrm{KU} / \mathrm{L}$. According to the manufacturer, the IMA upper limit of normal is $85 \mathrm{KU} / \mathrm{L}$ as determined by the $95^{\text {th }}$ percentile of a population of 283 apparently healthy individuals.

\section{Statistical Analysis}

Continuous variables were expressed as mean $\pm 1 \mathrm{SD}$ and differences between groups determined with unpaired $t$ test. Categorical variables were compared using $\chi^{2}$ analysis or Fisher's exact test. Stepwise binary logistic regression analysis was used to determine whether the difference in IMA levels at baseline and peak stress was a good predictor of the DSE result. The optimal IMA cut off value for ischaemia diagnosis was determined from receiver operator characteristics (ROC) analysis. The area under the curve (AUC) for ischaemia diagnosis by peak IMA and IMA rise were calculated and compared. Pearson's correlation coefficient was calculated for the correlation of continuous variables with peak IMA concentration. All statistical tests were two-tailed with a $\mathrm{p}$ value $<0.05$ to indicate statistical significance. The level of agreement between 2 observers analysed using kappa statistics. The SPSS statistics package (SPSS Inc, version 12, Chicago, IL, USA) was used. 


\section{Follow-Up}

Follow-up of clinical status was obtained by review of inpatient and outpatient medical records and telephone calls to the transplant unit. The survival status and cause of death of all patients was known at the time of follow up.

\section{RESULTS}

\section{Baseline Characteristics}

Of 117 renal transplant candidates screened, 1 was excluded for severe aortic stenosis, 2 refused to consent for the study. Thus, 114 patients were enrolled. The baseline characteristics are shown in Table 1. Diabetes (40\%) was the leading cause of renal failure and 55\% were on dialysis. 81 (71\%) patients had residual urine production. The mean estimated GFR was $13 \pm 6 \mathrm{mls} /$ minute. 23 (20\%) had impaired left ventricular function $(\mathrm{LVEF}<50 \%)$ but none had severe impairment (LVEF $<30 \%)$. $34(30 \%)$ patients had severe CAD. Medication use included aspirin in 51 patients (45\%), beta blockers in 40 patients $(35 \%)$, angiotensin - converting enzyme inhibitors in 53 patients $(46 \%)$, statins in 58 patients $(51 \%)$, erythropoetin in 60 patients $(53 \%)$, diuretic in 49 patients (44\%). Medication was not adjusted in relation to DSE or coronary angiogram results. Eight patients had coronary artery bypass surgery and 11 percutaneous intervention. The decision for revascularisation was driven by the DSE results.

\section{Differences in biomarker levels according to the ischaemic response}

Table 2 shows baseline and peak biomarker levels in those with and without a positive DSE. Baseline and peak IMA and baseline cTnT levels were not significantly 
different in the DSE positive and negative groups. Mean IMA levels rose with stress in both the DSE positive and negative groups $(85.4 \pm 18.1 \mathrm{KU} / \mathrm{L}$ to $107.9 \pm 29.1 \mathrm{KU} / \mathrm{L}$ and $87.1 \pm 26.6 \mathrm{KU} / \mathrm{L}$ to $95.1 \pm 26.5 \mathrm{KU} / \mathrm{L}$ respectively). The rise in IMA with stress was significantly higher in the DSE positive group compared to those with no inducible ischaemia $(26.5 \pm 19.9 \mathrm{KU} / \mathrm{L}$ vs $8.2 \pm 9.6 \mathrm{KU} / \mathrm{L}, \mathrm{p}=0.007)$. The baseline cTnT was similar in the DSE positive and DSE negative groups.

\section{IMA as a marker of ischaemia during dobutamine stress}

Binary logistic regression analysis showed that the rise of IMA during DSE is a good predictor of the DSE result (OR $5.1 \pm 0.06,95 \%$ CI 1.7, 8.4, $\mathrm{p}=0.005)$. Linear Regression analysis showed the magnitude of IMA rise was a good predictor of the severity of ischaemic response as measured by the peak WMSI $\left(r^{2}=0.71, p=0.008\right.$, 95\% CI 0.001, 0.008).

\section{The optimal IMA rise for ischaemia diagnosis}

From ROC analysis, optimal peak IMA concentration to predict an ischaemic response was $95 \mathrm{KU} / \mathrm{L}$, with sensitivity $76 \%$ and specificity $38 \%(\mathrm{AUC}=0.66,95 \%$ CI $0.41-0.83, \mathrm{p}=0.06$ ). This is shown in figure 1 . From ROC analysis, the optimal IMA rise to predict an ischaemic response was $20 \mathrm{KU} / \mathrm{L}$, with sensitivity $81 \%$ and specificity $72 \%(\mathrm{AUC}=0.80,95 \% \mathrm{CI} 0.44-0.94, \mathrm{p}=0.04)$. This is shown in figure 2. Positive and negative predictive values of IMA rise $\geq 20 \mathrm{KU} / \mathrm{L}$ for ischaemia diagnosis were $82 \%$ and $73 \%$ respectively. The IMA rise during DSE was a significantly better marker of ischaemia than peak IMA when the AUC of each were compared ( 0.80 vs $0.62, p=0.02)$. Thirty - seven $(32 \%)$ patients developed an IMA rise $\geq 20 \mathrm{KU} / \mathrm{L}$ during DSE. 


\section{Correlates of peak IMA concentration}

There was a significant positive correlation between the peak IMA concentration and LV end systolic diameter $(r=0.42, p=0.03)$, left atrial diameter $(r=0.47, p=0.05)$ and mitral E/Ea ratio $(r=0.47, p=0.04)$. There was a negative correlation with LV ejection fraction $(\mathrm{r}=-0.54, \mathrm{p}=0.02)$ and albumin $(\mathrm{r}=-0.43, \mathrm{p}=0.03)$. There was no correlation with age, cholesterol, haemoglobin or cTnT.

\section{The IMA rise as a marker of mortality}

Mean follow - up time was $2.25 \pm 0.71$ years (range 0.19 to 3.27 years). 38 patients received their renal transplant, 7 taken off the transplant list. There were 18 deaths, 10 of which were cardiac (myocardial infarction in 8 , heart failure in 2). Mean time to death was $0.97 \pm 0.45$ years (range 0.19 to 3.15 years). Differences between survivors and non survivors are shown in table 3. Non survivors were older and a significantly higher proportion were diabetic, had severe CAD and positive DSE result. Peak stress IMA concentrations and the IMA rise during DSE were significantly higher in non survivors. Left ventricular cavity dimensions were larger, systolic function lower, LA size larger and estimated LV filling pressures higher in non survivors. From Kaplan Meier survival analysis, patients with an IMA rise $\geq 20 \mathrm{KU} / \mathrm{L}$ during DSE had significantly greater mortality than those with a rise $<20 \mathrm{KU} / \mathrm{L}(\mathrm{p}=0.02 \log$ rank test). This is shown in figure 3. Cardiac mortality was also significantly higher in those with a significant IMA rise $\geq 20 \mathrm{KU} / \mathrm{L}$ during DSE compared to those without $(\mathrm{p}=0.03, \log$ rank test $)$ 


\section{DISCUSSION}

This is the first study to propose IMA as a marker for early myocardial ischaemia diagnosis in ESRD. Dobutamine stress was used to provoke an ischaemic response in a group of renal transplant candidates. We have previously shown this technique is highly accurate for CAD diagnosis in ESRD.[13] We found the rise in IMA during stress was a moderately accurate marker for myocardial ischaemia diagnosis. The magnitude of IMA rise correlated with the severity of the ischaemic response. An IMA rise $\geq 20 \mathrm{KU} / \mathrm{L}$ during DSE was associated with total and cardiac mortality. However, an isolated peak IMA concentration $\geq 95 \mathrm{KU} / \mathrm{L}$ had moderate sensitivity but low specificity for ischaemia diagnosis. Baseline cTnT levels did not predict an ischaemic response with dobutamine stress. This was an exploratory study. Further studies, with larger sample sizes, are required to validate our findings and to establish IMA cut off values that may be used in the clinical setting.

\section{IMA as a marker of ischaemia}

IMA, measured by the albumin cobalt binding test, is a marker of ischaemia.[22] The $\mathrm{N}$-terminus of albumin is damaged during an ischemic event, resulting in IMA. IMA is unable to bind metals at the N-terminus. In the ACB assay a known amount of cobalt is added to the sample. Upon reacting with dithiothreitol, any unbound cobalt forms a coloured complex. This is measured spectrophotometrically and is proportional to the amount of IMA present in the sample. Serum concentrations of IMA rise acutely after percutaneous coronary intervention[10] and in patients with spontaneous ischaemia.[23] Its exact role in the risk stratification of patients with acute chest pain has yet to be defined. Using DSE to provoke an ischaemic response, 
the rise in IMA from baseline was independently associated with the DSE result in a group of patients with ESRD. Moreover, the magnitude of rise was a significant predictor of the severity of ischaemic response. These findings are comparable to previous studies in non uraemic patients showing a rise in IMA in those with chest pain and ECG changes after percutaneous angioplasty.[10, 22, 24] The peak optimal IMA cut off value for myocardial ischaemia diagnosis in this population, $95 \mathrm{KU} / \mathrm{L}$, had moderate sensitivity but low specificity. This low specificity of IMA has been reported in non uraemic patients. IMA is not specific for myocardial ischaemia. Serum concentrations are elevated in skeletal muscle ischaemia and should be interpreted with caution in patients with peripheral vascular disease.[25] However, we did find an IMA rise $\geq 20 \mathrm{KU} / \mathrm{L}$ had both better sensitivity (81\%) and specificity (72\%) for myocardial ischaemia diagnosis.

In this study, the detection of ischaemia using an IMA rise was also predictive of total and cardiac mortality. There was a positive correlation with peak IMA concentration and left ventricular diameter and estimated left ventricular filling pressure. There was a negative correlation with left ventricular ejection fraction and albumin. These associations may at least in part contribute to the observed greater mortality in patients with a high IMA rise during dobutamine stress.

For application in the emergency setting, the absence of a pre-ischaemic baseline value means the peak IMA and not IMA rise would be required to diagnose ischaemia. Our study, like others, has shown a single peak IMA cut off value has only moderate sensitivity and low specificity for myocardial ischaemia diagnosis in ESRD. Further studies, in a larger number of patients presenting to the emergency department 
with chest pain, are required to determine whether cut off values for IMA can be derived with better sensitivity and specificity for myocardial ischaemia diagnosis in this patient group. It is possible that two IMA values will be required with high sensitivity and low specificity and high specificity and low sensitivity respectively. This may allow a 'rule in' and 'rule out' diagnosis for myocardial ischaemia using IMA. The sample size of this exploratory study is too small to provide such values for a clinical setting. However, our work does suggest IMA has a potential role for ischaemia diagnosis in ESRD.

\section{Markers of ischaemia in ESRD}

The need for early diagnosis of myocardial ischaemia in patients with ESRD is critical given the high mortality untreated. In this study, baseline cTnT levels did not predict an ischaemic response with DSE despite the fact that this is a marker of increased mortality in ESRD.[26] Cardiac troponins are elevated in a proportion of patients with ESRD and a single measurement is less sensitive for myocardial ischaemia diagnosis. Indeed, $46 \%$ of our population had baseline cTnT concentrations above the value recommended for myocardial infarction diagnosis.[19] Serial troponin measurements are recommended for the diagnosis of ACS in patients with renal failure.[27] However, this results in a delay in the diagnosis. Creatine kinase and creatine kinase $\mathrm{MB}$ isoenzyme are also elevated in a proportion of dialysis patients so are less sensitive for ischaemia diagnosis in ESRD.[28] The resting ECG is abnormal in up to $65 \%$ of patients receiving dialysis.[7] Consequently, the ECG has lower sensitivity for ischaemia diagnosis in this patient group.[29] Silent ischaemia and chest pain with unobstructed coronary arteries are common in renal failure.[6, 29, 30] Cardiac symptoms are thus less reliable for ischaemia diagnosis. The need for a 
reliable marker of ischaemia in ESRD is therefore high. This study highlights the potential of IMA for this purpose.

\section{Study Limitations}

The main study limitation was the small sample size. The number of patients with cardiac deaths was only 10 . This is too small for the evaluation of the IMA rise during DSE as a predictor of mortality by multivariate Cox proportional hazards regression analysis. Larger scale studies are required to validate our findings and show any incremental prognostic information IMA provides over existing risk stratification tools in ESRD. Additional limitations include the absence of a later IMA sample showing a dynamic return to baseline, and the post hoc application of a cut-point from exploratory analysis.

\section{Conclusion}

IMA rises during dobutamine stress and is a moderately accurate marker of myocardial ischaemia during stress testing in ESRD. Patients with an IMA rise $\geq 20$ KU/L during DSE have significantly worse survival. 


\section{REFERENCES}

1. Herzog CA, Ma JZ, Collins AJ: Poor long-term survival after acute myocardial infarction among patients on long-term dialysis. $N$ Engl $J$ Med 339:799-805, 1998

2. Wright RS, Reeder GS, Herzog CA, Albright RC, Williams BA, Dvorak DL, Miller WL, Murphy JG, Kopecky SL, Jaffe AS: Acute myocardial infarction and renal dysfunction: a high-risk combination. Ann Intern Med 137:563-570., 2002

3. Gibson CM, Pinto DS, Murphy SA, Morrow DA, Hobbach HP, Wiviott SD, Giugliano RP, Cannon CP, Antman EM, Braunwald E: Association of creatinine and creatinine clearance on presentation in acute myocardial infarction with subsequent mortality. J Am Coll Cardiol 42:1535-1543, 2003

4. Al Suwaidi J, Reddan DN, Williams K, Pieper KS, Harrington RA, Califf RM, Granger CB, Ohman EM, Holmes DR, Jr.: Prognostic implications of abnormalities in renal function in patients with acute coronary syndromes. Circulation 106:974-980, 2002

5. Januzzi JL, Jr., Snapinn SM, DiBattiste PM, Jang IK, Theroux P: Benefits and safety of tirofiban among acute coronary syndrome patients with mild to moderate renal insufficiency: results from the Platelet Receptor Inhibition in Ischemic Syndrome Management in Patients Limited by Unstable Signs and Symptoms (PRISM-PLUS) trial. Circulation 105:2361-2366, 2002

6. Braun WE, Marwick TH: Coronary artery disease in renal transplant recipients. Cleve Clin J Med 61:370-385, 1994 
7. Abe S, Yoshizawa M, Nakanishi N, Yazawa T, Yokota K, Honda M, Sloman G: Electrocardiographic abnormalities in patients receiving hemodialysis. Am Heart J 131:1137-1144, 1996

8. Wu AH, Feng YJ, Roper L, Herbert K, Schweizer R: Cardiac troponins T and I before and after renal transplantation. Clin Chem 43:411-412, 1997

9. Musso P, Cox I, Vidano E, Zambon D, Panteghini M: Cardiac troponin elevations in chronic renal failure: prevalence and clinical significance. Clin Biochem 32:125-130, 1999

10. Sinha MK, Gaze DC, Tippins JR, Collinson PO, Kaski JC: Ischemia modified albumin is a sensitive marker of myocardial ischemia after percutaneous coronary intervention. Circulation 107:2403-2405, 2003

11. Pollack C, Peackock W, Summers R, Fesmire F, Holroy B, Kirk J, Mannion T: Ischemia-modified Albumin is useful in Risk Stratification of Emegergency Department Chest Pain Patients. Acad Emerg Med 10:555-556, 2003

12. Sharma R, Gaze DC, Pellerin D, Mehta RL, Gregson H, Streather CP, Collinson PO, Brecker SJ: Ischemia-modified albumin predicts mortality in ESRD. Am J Kidney Dis 47:493-502, 2006

13. Sharma R, Pellerin D, Gaze DC, Shah JS, Streather CP, Collinson PO, Brecker SJ: Dobutamine stress echocardiography and cardiac troponin T for the detection of significant coronary artery disease and predicting outcome in renal transplant candidates. Eur J Echocardiogr 6:327 - 335, 2005

14. Harnett JD, Murphy B, Collingwood P, Purchase L, Kent G, Parfrey PS: The reliability and validity of echocardiographic measurement of left ventricular mass index in hemodialysis patients. Nephron 65:212-214, 1993 
15. Schiller NB, Shah PM, Crawford M, DeMaria A, Devereux R, Feigenbaum H, Gutgesell H, Reichek N, Sahn D, Schnittger I, et al.: Recommendations for quantitation of the left ventricle by two-dimensional echocardiography. American Society of Echocardiography Committee on Standards, Subcommittee on Quantitation of Two-Dimensional Echocardiograms. $J$ Am Soc Echocardiogr 2:358-367, 1989

16. Ommen SR, Nishimura RA, Appleton CP, Miller FA, Oh JK, Redfield MM, Tajik AJ: Clinical utility of Doppler echocardiography and tissue Doppler imaging in the estimation of left ventricular filling pressures: A comparative simultaneous Doppler-catheterization study. Circulation 102:1788-1794, 2000

17. Armstrong WF: Stress echocardiography for detection of coronary artery disease. Circulation 84:I43-49, 1991

18. Hallermayer K, Klenner D, Vogel R: Use of recombinant human cardiac Troponin T for standardization of third generation Troponin T methods. Scand J Clin Lab Invest Suppl 230:128-131, 1999

19. Collinson PO, Stubbs PJ, Kessler AC: Multicentre evaluation of the diagnostic value of cardiac troponin T, CK-MB mass, and myoglobin for assessing patients with suspected acute coronary syndromes in routine clinical practice. Heart 89:280-286, 2003

20. Christenson RH, Duh SH, Sanhai WR, Wu AH, Holtman V, Painter P, Branham E, Apple FS, Murakami M, Morris DL: Characteristics of an Albumin Cobalt Binding Test for assessment of acute coronary syndrome patients: a multicenter study. Clin Chem 47:464-470, 2001

21. Wu AH, Morris DL, Fletcher DR, Apple FS, Christenson RH, Painter PC: Analysis of the Albumin Cobalt Binding (ACB) test as an adjunct to cardiac 
troponin I for the early detection of acute myocardial infarction. Cardiovasc Toxicol 1:147-151, 2001

22. Bar-Or D, Winkler JV, Vanbenthuysen K, Harris L, Lau E, Hetzel FW: Reduced albumin-cobalt binding with transient myocardial ischemia after elective percutaneous transluminal coronary angioplasty: a preliminary comparison to creatine kinase-MB, myoglobin, and troponin I. Am Heart J $141: 985-991,2001$

23. Bhagavan NV, Lai EM, Rios PA, Yang J, Ortega-Lopez AM, Shinoda H, Honda SA, Rios CN, Sugiyama CE, Ha CE: Evaluation of human serum albumin cobalt binding assay for the assessment of myocardial ischemia and myocardial infarction. Clin Chem 49:581-585, 2003

24. Quiles J, Roy D, Gaze D, Garrido IP, Avanzas P, Sinha M, Kaski JC: Relation of ischemia-modified albumin (IMA) levels following elective angioplasty for stable angina pectoris to duration of balloon-induced myocardial ischemia. Am J Cardiol 92:322-324, 2003

25. Roy D, Quiles J, Sharma R, Sinha M, Avanzas P, Gaze D, Kaski JC: Ischemia modified albumin concentrations in patients with peripheral vascular disease and exercise induced skeletal muscle ischaemia. Clin Chem 50:1656-1660, 2004

26. Dierkes J, Domrose U, Westphal S, Ambrosch A, Bosselmann HP, Neumann $\mathrm{KH}$, Luley C: Cardiac troponin T predicts mortality in patients with end-stage renal disease. Circulation 102:1964-1969., 2000

27. Collinson PO, Hadcocks L, Foo Y, Rosalki SB, Stubbs PJ, Morgan SH, O'Donnell J: Cardiac troponins in patients with renal dysfunction. Ann Clin Biochem 35 ( Pt 3):380-386, 1998 
28. Green TR, Golper TA, Swenson RD, Pulliam JP, Morris CD: Diagnostic value of creatine kinase and creatine kinase $\mathrm{MB}$ isoenzyme in chronic hemodialysis patients: a longitudinal study. Clin Nephrol 25:22-27, 1986

29. Sharma R, Pellerin D, Gaze DC, Gregson H, Streather CP, Collinson PO, Brecker SJ: Dobutamine stress echocardiography and the resting but not exercise electrocardiograph predict severe coronary artery disease in renal transplant candidates. Nephrol Dial Transplant 20:2207-2214, 2005

30. Mohi-ud-din K, Bali HK, Banerjee S, Sakhuja V, Jha V: Silent myocardial ischemia and high-grade ventricular arrhythmias in patients on maintenance hemodialysis. Ren Fail 27:171-175, 2005 


\section{FIGURE LEGENDS}

Figure 1. ROC Curve for the peak IMA concentration during DSE that predicts an ischaemic response in patients with ESRD (for abbreviations see text).

Figure 2. ROC Curve for the IMA rise during DSE that predicts an ischaemic response in patients with ESRD (for abbreviations see text).

Figure 3. Kaplan - Meier Survival according to IMA Rise $>10 \mathrm{KU} / \mathrm{L}$ during dobutamine stress (for abbreviations see text). 
Table 1. Baseline Characteristics

\begin{tabular}{|c|c|}
\hline Age (years) & $52 \pm 12(44-76)$ \\
\hline Sex & 76 male $(67 \%) ; 38$ female $(33 \%)$ \\
\hline Ethnicity & $\begin{array}{l}\text { Caucasian } 51(45 \%) \\
\text { Asian } 27(24 \%) \\
\text { AfroCarribean } 33(29 \%) \\
\text { Chinese 2; Other } 1\end{array}$ \\
\hline Serum Creatinine $(\mu \mathrm{mol} / \mathrm{L})$ & $608 \pm 272(254-1328)$ \\
\hline Serum Haemoglobin $(\mathrm{g} / \mathrm{L})$ & $10.2 \pm 1.6(8-14)$ \\
\hline Cholesterol $(\mathrm{mmol} / \mathrm{L})$ & $4.9 \pm 1.8(1.4-15)$ \\
\hline $\operatorname{cTnT}(\mu \mathrm{g} / \mathrm{L})$ & $0.08 \pm 0.05(0-1.08)$ \\
\hline IMA (KU/L) & $88 \pm 29(39-164)$ \\
\hline Serum Albumin (mmol/L) & $36 \pm 7(21-44)$ \\
\hline $\mathrm{cTnT} \geq 0.05 \mu \mathrm{g} / \mathrm{L}$ & $53(46 \%)$ \\
\hline ESRD cause & $\begin{array}{l}\text { Diabetes } 46(40 \%) \\
\text { Glomerulonephritis } 24(21 \%) \\
\text { Hypertension } 14(12 \%) \\
\text { APCKD } 13(11 \%) \\
\text { Obstructive Uropathy } 10(9 \%) \text { Other } 7(5 \%)\end{array}$ \\
\hline Dialysis Modality & $\begin{array}{l}\text { Predialysis } 48(42 \%) \\
\text { Haemodialysis } 43(38 \%) \\
\text { Peritoneal Dialysis } 23(20 \%)\end{array}$ \\
\hline Dialysis Time (months) & $2.73 \pm 2.19(0-11)$ \\
\hline Previous Transplant & $13(11 \%)$ \\
\hline $\begin{array}{l}\text { Cardiac Symptoms } \\
\text { NYHA Class } 1 \\
\text { NYHA Class } 2 \\
\text { NYHA Class } 3 \text { and } 4\end{array}$ & $\begin{array}{l}52(46 \%) \\
35(31 \%) \\
17(15 \%) \\
0\end{array}$ \\
\hline Diabetes & $\begin{array}{r}46(40 \%) 20 \text { Type } 1 \\
26 \text { Type } 2\end{array}$ \\
\hline Hypertension & $105(92 \%)$ \\
\hline Raised cholesterol & $59(52 \%)$ \\
\hline Smoker & $14(12 \%)$ \\
\hline Pre-existing Cardiac Disease & $\begin{array}{l}\text { Ischaemic Heart Disease } 12(11 \%) \\
\text { Heart Failure } 10(8 \%)\end{array}$ \\
\hline Severe CAD & $34(30 \%)$ \\
\hline Positive DSE Result & $35(31 \%)$ \\
\hline
\end{tabular}

Abbreviations: cTnT, cardiac troponin T; DSE, dobutamine stress echocardiogram;

CAD, coronary artery disease; APCKD, adult polycystic kidney disease; IMA, ischemia modified albumin; NYHA, New York Heart Association Classification 
Table 2. Biomarker concentrations of patients with and without inducible ischaemia during DSE

\begin{tabular}{|l|l|l|l|}
\hline & Positive DSE & Negative DSE & P value \\
& $(\mathrm{n}=35)$ & $0.07 \pm 0.05$ & 0.21 \\
\hline Baseline cTnT $(\mu \mathrm{g} / \mathrm{L})$ & $0.11 \pm 0.07$ & $0.01 \pm 0.02$ & 0.73 \\
\hline cTnT Change $(\mu \mathrm{g} / \mathrm{L})$ & $0.01 \pm 0.02$ & & \\
\hline Baseline IMA $(\mathrm{KU} / \mathrm{L})$ & $85.4 \pm 18.1$ & $87.1 \pm 26.6$ & 0.41 \\
\hline Peak Stress IMA (KU/L) & $107.9 \pm 29.1$ & $95.1 \pm 26.5$ & 0.18 \\
\hline IMA Change (KU/L) & $26.5 \pm 19.1$ & $8.2 \pm 9.6$ & 0.007 \\
\hline
\end{tabular}

For abbreviations: see text. 
Table 3. Comparison of Survivors and Non Survivors

\begin{tabular}{|c|c|c|c|}
\hline PARAMETER & SURVIVORS & $\begin{array}{l}\text { NON } \\
\text { SURVIVORS }\end{array}$ & $* \mathrm{P}$ value \\
\hline Number & $96(88 \%)$ & $18(16 \%)$ & \\
\hline Age & $50 \pm 13$ & $59 \pm 12$ & 0.05 \\
\hline Male & $66(61 \%)$ & $10(55 \%)$ & 0.69 \\
\hline Female & $30(31 \%)$ & $8(44 \%)$ & 0.61 \\
\hline Smoker & $10(11 \%)$ & $4(22 \%)$ & 0.57 \\
\hline Hypertension & $90(92 \%)$ & $15(83 \%)$ & 0.88 \\
\hline Raised Cholesterol & $50(44 \%)$ & $9(50 \%)$ & 0.71 \\
\hline Diabetes & $31(33 \%)$ & $15(83 \%)$ & $<0.001$ \\
\hline Previous Renal Transplant & $9(11 \%)$ & $4(22 \%)$ & 0.11 \\
\hline Dialysis & $56(58 \%)$ & $10(55 \%)$ & 0.74 \\
\hline Dialysis Time (months) & $2.58 \pm 1.26$ & $2.85 \pm 1.66$ & 0.26 \\
\hline Body Mass Index $\left(\mathrm{g} / \mathrm{m}^{2}\right)$ & $25 \pm 16$ & $24 \pm 10$ & 0.89 \\
\hline Systolic BP (mmHg) & $145 \pm 18$ & $148 \pm 10$ & 0.66 \\
\hline Diastolic BP (mmHg) & $76 \pm 11$ & $83 \pm 9$ & 0.49 \\
\hline Cholesterol (mmol/L) & $4.90 \pm 1.24$ & $4.51 \pm 1.16$ & 0.32 \\
\hline Haemoglobin $(\mathrm{g} / \mathrm{dL})$ & $11.2 \pm 1.4$ & $11.7 \pm 1.3$ & 0.68 \\
\hline Creatinine $(\mu \mathrm{mol} / \mathrm{L})$ & $585 \pm 278$ & $646 \pm 238$ & 0.35 \\
\hline Calcium $(\mathrm{mmol} / \mathrm{L})$ & $2.35 \pm 0.26$ & $2.38 \pm 0.23$ & 0.74 \\
\hline Phosphate (mmol/L) & $1.74 \pm 0.38$ & $1.68 \pm 0.34$ & 0.86 \\
\hline Albumin $(\mathrm{mmol} / \mathrm{L})$ & $37 \pm 15$ & $34 \pm 19$ & 0.37 \\
\hline $\operatorname{cTnT}(\mu \mathrm{g} / \mathrm{L})$ & $0.07 \pm 0.04$ & $0.16 \pm 0.08$ & 0.02 \\
\hline Peak Stress IMA (KU/L) & $88 \pm 31$ & $109 \pm 28$ & 0.04 \\
\hline IMA Rise During Stress (KU/L) & $10 \pm 6$ & $29 \pm 12$ & 0.009 \\
\hline LVESD $(\mathrm{cm})$ & $2.8 \pm 0.8$ & $3.7 \pm 0.9$ & 0.008 \\
\hline LVEDD (cm) & $4.7 \pm 0.9$ & $5.7 \pm 1.2$ & 0.007 \\
\hline LVEF (\%) & $68 \pm 13$ & $52 \pm 14$ & 0.006 \\
\hline Left Atrium (cm) & $3.8 \pm 0.6$ & $4.4 \pm 0.7$ & 0.002 \\
\hline Mitral E/Ea Ratio & $11.2 \pm 4.2$ & $19.1 \pm 8.2$ & 0.009 \\
\hline Positive DSE Result & $25(26 \%)$ & $10(55 \%)$ & 0.01 \\
\hline Severe CAD & $24(23 \%)$ & $10(55 \%)$ & 0.02 \\
\hline
\end{tabular}

Abbreviations: cTnT, cardiac troponin T; DSE, dobutamine stress echocardiogram; CAD, coronary artery disease; $\mathrm{BP}$, blood pressure; IMA, ischemia modified albumin; LVESD, left ventricular end systolic diameter; LVEDD, left ventricular end diastolic diameter; LVEF, left ventricular ejection fraction. 

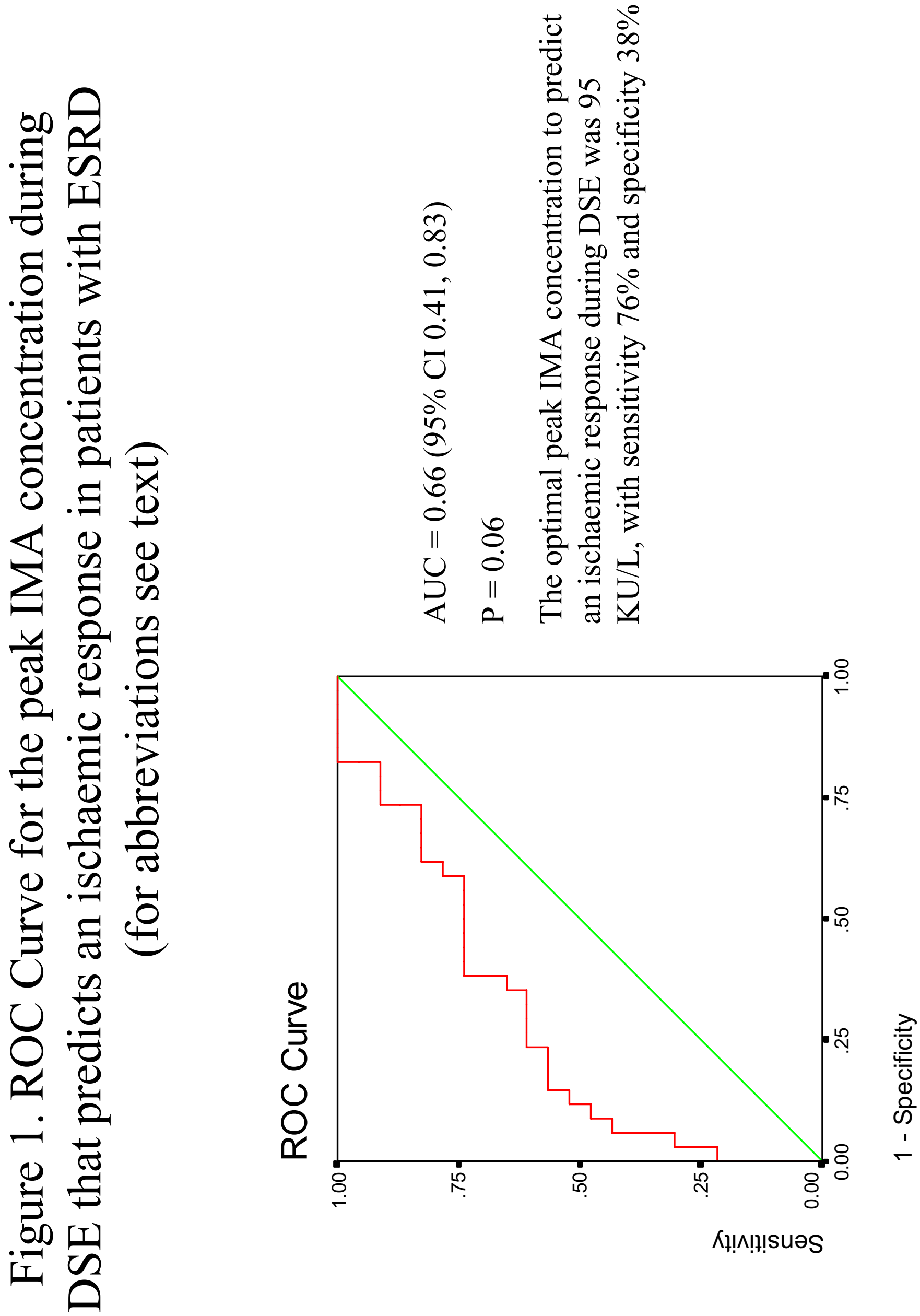


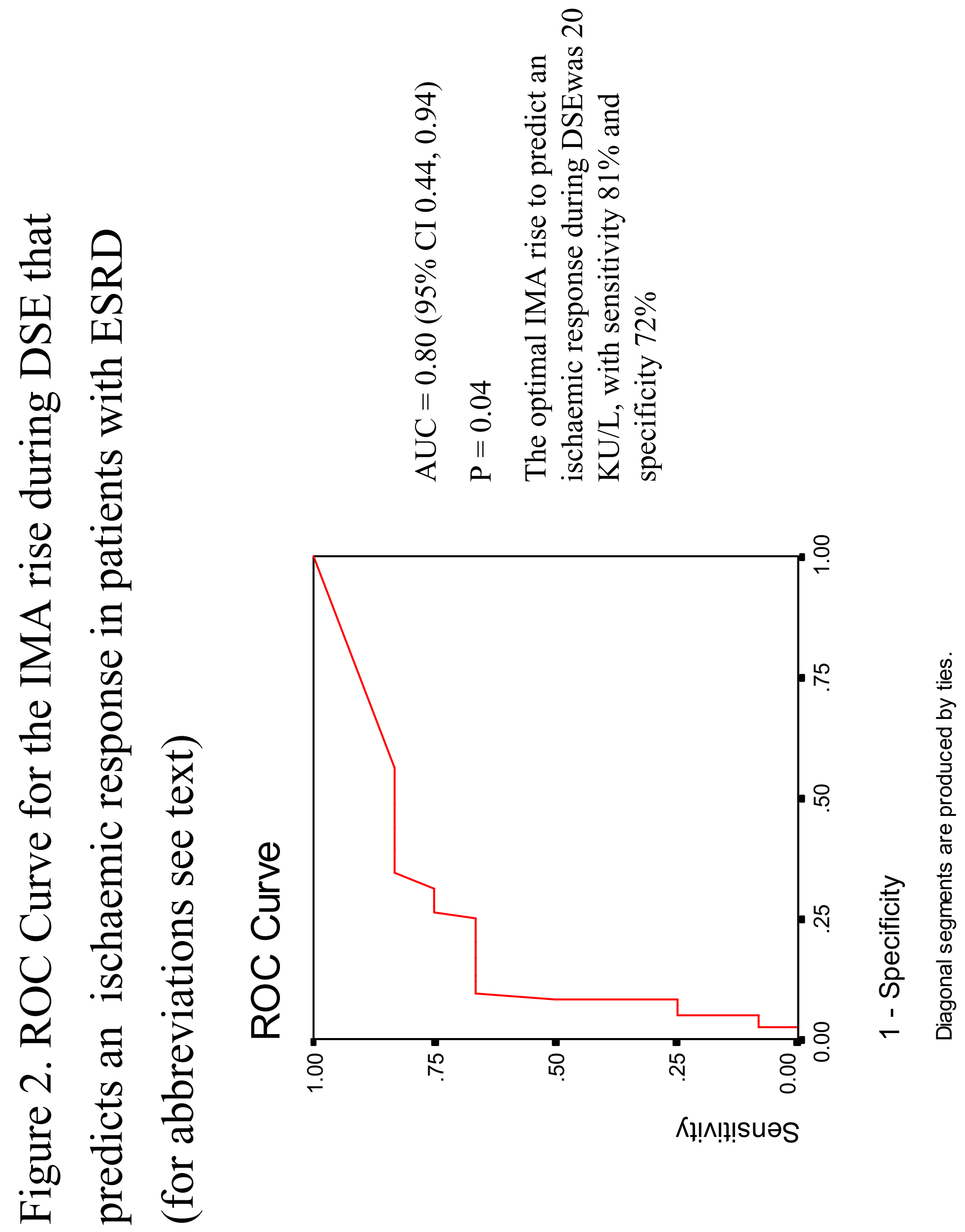




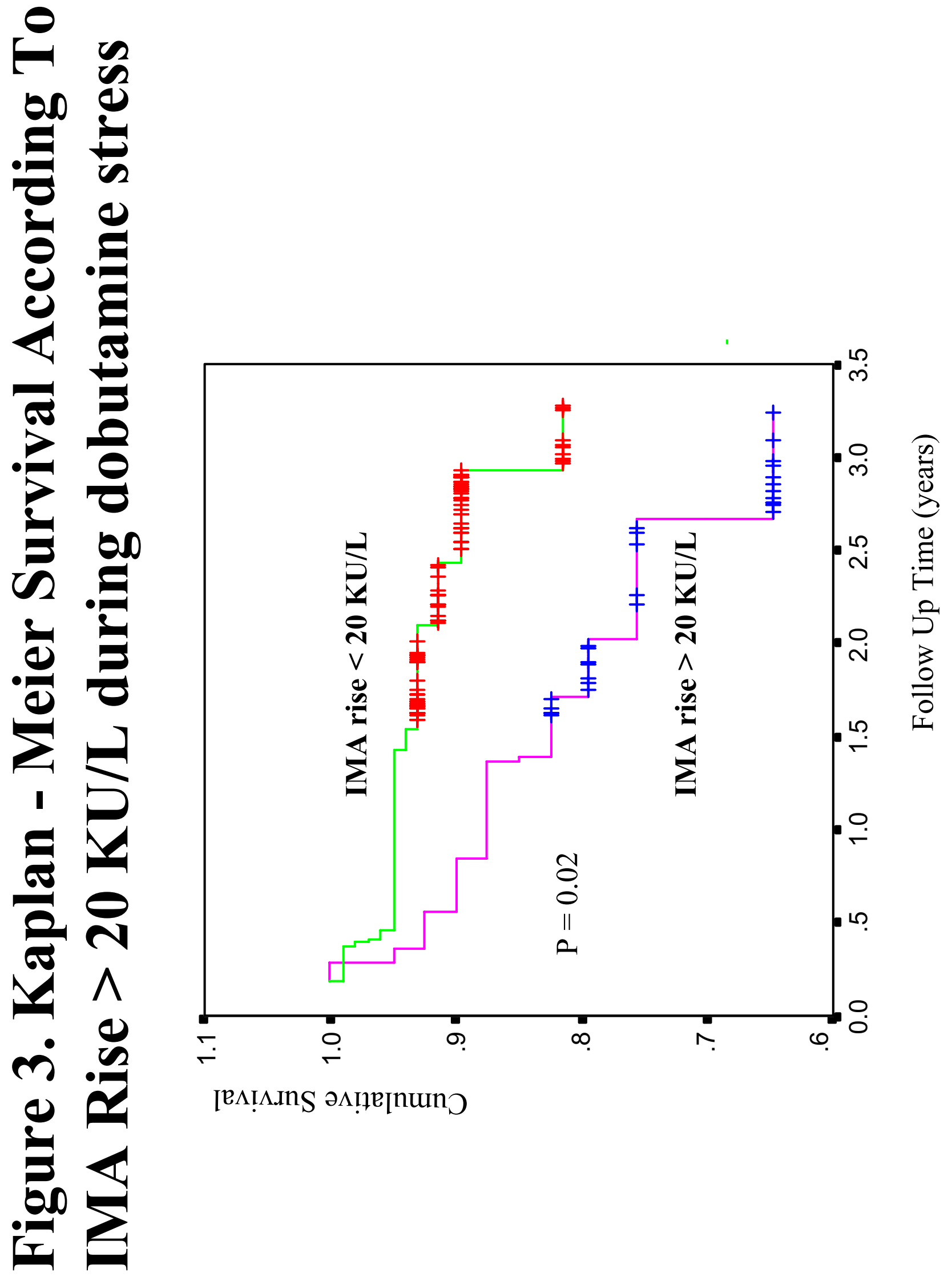

